OPEN ACCESS

Edited by:

Tuyeni Heita Mwampamba,

National Autonomous University of

Mexico, Mexico

Reviewed by:

Stephen J. Ventura,

University of Wisconsin-Madison,

United States

Martin Zimmer,

Leibniz Centre for Tropical Marine

Research (LG), Germany

*Correspondence:

Mario Giampietro

mario.giampietro@uab.cat

Specialty section:

This article was submitted to Agroecology and Land Use Systems,

a section of the journal

Frontiers in Environmental Science

Received: 22 February 2017 Accepted: 14 August 2017

Published: 29 August 2017

Citation:

González-López R and Giampietro M (2017) Multi-Scale Integrated Analysis of Charcoal Production in Complex Social-Ecological Systems.

Front. Environ. Sci. 5:54

doi: 10.3389/fenvs.2017.00054

\section{Multi-Scale Integrated Analysis of Charcoal Production in Complex Social-Ecological Systems}

\author{
Rafael González-López ${ }^{1}$ and Mario Giampietro ${ }^{1,2 *}$ \\ 1 Institut de Ciència i Tecnologia Ambientals, Universitat Autònoma de Barcelona, Bellaterra, Spain, ${ }^{2}$ Institució Catalana de \\ Recerca i Estudis Avançats, Barcelona, Spain
}

We propose and illustrate a multi-scale integrated analysis of societal and ecosystem metabolism (MUSIASEM) as a tool to bring nexus thinking into practice. MuSIASEM studies the relations over the structural and functional components of social-ecological systems that determine the entanglement of water, energy, and food flows in a complex metabolic pattern. MuSIASEM simultaneously considers various dimensions and multiple scales of analysis and therefore avoids the predicament of quantitative analysis based on reductionism (one dimension and one scale at the time). The different functional elements of society (the parts) are characterized using the concept of "processor," that is, a profile of expected inputs and outputs associated with the expression of a specific function. The processors of the functional elements of the social-ecological system can be either scaled-up to describe the metabolic pattern of the system as a whole, or scaled-down by considering the characteristics of its lower-level parts-i.e., the different processors associated with the structural elements required to express the specific function. An analysis of functional elements provides insight in the socio-economic factors that pose internal constraints on the development of the system. An analysis of structural elements makes it possible to study the compatibility of the system with external constraints (availability of natural resources and ecological services) in spatial terms. The usefulness of the approach is illustrated in relation to an example of the use of charcoal in a rural village of Laos.

\section{Keywords: charcoal, metabolic pattern, relational analysis, social-ecological system, MuSIASEM}

\section{INTRODUCTION}

Multi-scale integrated analysis of societal and ecosystem metabolism (MUSIASEM) is a general accounting framework for the analysis of the metabolic pattern of social-ecological systems (Giampietro et al., 2009, 2014). MuSIASEM allows the simultaneous consideration of water, energy, and food flows over various hierarchical scales of analysis, and therefore is a potentially powerful tool to bring nexus thinking into practice. Indeed, according to UNU-FLORES (https://flores.unu. edu/en/research/nexus) a nexus approach "examines the inter-relatedness and interdependencies of environmental resources and their transitions and fluxes across spatial scales and between compartments." The potential use of MuSIASEM to study water-energy-food nexus problems has been explored earlier (Giampietro et al., 2014), but not in relation to charcoal production in tropical social-ecological systems. In this work we illustrate a refinement of the MuSIASEM approach as 
recently developed in the EU Horizon2020 project MAGIC. This particular approach relies on the use of software and the creation of an ad-hoc database. For reasons of space, these technical aspects are not presented here. However, detailed technical descriptions of other pilot case studies, representing various types of social-ecological systems at different hierarchical scales, are available in deliverable D4.1 of MAGIC (http://magic-nexus.eu/).

Charcoal production plays an important role as a source of energy and cash income for populations of many developing countries, notably in Africa. However, charcoal production is increasingly being associated to deforestation and environmental degradation (Mwampamba et al., 2013) and therefore is now often included in the list of "dangerous" activities (Zulu, 2010). In order to seek sustainable solutions, it is important to recognize that charcoal production forms an integral part of a complex network of activities that operates at different scales establishing a bridge between ecosystem services and the supply of key resources such as food, energy, and water (Chidumayo and Gumbo, 2013). Moreover in many socio economic circumstances charcoal production is associated with a rich diversity of stakeholders across its supply chain (Butz, 2013; Ghilardi et al., 2013; Zulu and Richardson, 2013). These various aspects make charcoal production a perfect case study for MuSIASEM.

In this work, we adapt the MuSIASEM approach to study the water-energy-food nexus in charcoal-producing rural systems. We use a novel concept, that of "processor" (defined below) that brings the relations among the system's elements into sharper focus. The concept of processor has been specifically developed by the second author within the context of the project MAGIC for the application of the MuSIASEM accounting scheme to the water-energy-food nexus. Using this idea of processor, we show in this paper how to characterize the metabolic pattern of water, energy and food of charcoal-producing systems by establishing a relation-in qualitative and quantitative termsamong: (1) the various functional components (e.g., subsistence production, cash crop production, charcoal production, off-farm work) associated with the survival/reproduction of the village (guaranteeing food, energy, and water security); and (2) the related structural elements (e.g., typologies of land-uses, aquifers, off-farm jobs) used to express the functions.

In the next section, we first provide the basic features of MuSIASEM. In the following Sections The Idea of Processors, Relational Analysis Over Functional Elements, and Relational Analysis Over Structural Elements we go more into the details of the methodological approach, and in Section Discussion and Conclusions we discuss the approach in relation to the specific problematics of charcoal-producing systems using a case study in Laos as an example.

\section{GENERAL FEATURES OF MULTI-SCALE INTEGRATED ANALYSIS OF SOCIETAL AND ECOSYSTEM METABOLISM}

The MuSIASEM accounting framework organizes quantitative information in reference to different dimensions of analysisi.e., social, economic, technical, biophysical, ecological-and different hierarchical scales of analysis referring to both socioeconomic narratives and an ecological narratives (Madrid-López and Giampietro, 2015). In this way, the information generated can be used to check three dimensions of sustainability:

1. Feasibility-This dimension sees the system (society) as a black-box interacting with its context. Feasibility thus refers to the compatibility of the metabolic system as a whole with processes beyond human control, that is, external constraints imposed by the availability of natural resources and ecosystem services. This dimension involves (i) checking whether the metabolism of the system (seen as a black box) is compatible with the boundary conditions, and (ii) checking the level of openness of the system in terms of trade with other social-ecological systems (the extent of externalization to or dependence on other social-ecological systems);

2. Viability-This dimension looks at the workings inside the black-box to check the interactions among its parts. Viability thus addresses the compatibility of the system in relation to processes under human control (e.g., economic viability, technical viability) by checking whether the interaction of the parts inside the black box is compatible with available technology and know-how;

3. Desirability-This dimension checks whether the characteristics of the metabolic pattern are acceptable to those living inside the system (the desirability of the metabolic pattern directly affects the stability of the social fabric).

MUSIASEM basically consists of a relational analysis of the functional and structural elements of a social-ecological system that together determine its metabolic pattern of water, energy, and food. The concept of metabolism is commonly associated to the human body to represent the complex processes converting food into the energy and building blocks required to maintain its structure and functions. However, the concept of metabolism can also be and indeed has been applied to social-ecological systems (Ostwald, 1907, 1911; Lotka, 1922, 1956; Soddy, 1926; Zipf, 1941; White, 1943; Cottrell, 1955). Complex societies exhibit a mechanism of reproduction and maintenance similar to that of the human body. They extract and use a mix of energy and material inputs from their environment to express the functions required for preserving their identity. Along these premises, a new scientific field has emerged that is based on the study of "societal (or social) metabolism" (Wolman, 1965; MartinezAlier, 1987; Fischer-Kowalski and Hüttler, 1998; Daniels, 2002; Swyngedouw, 2006; Giampietro et al., 2009; Broto et al., 2012; Giampietro, 2014). Metabolic pattern refers to the expected profile of inputs (taken from the environment) and outputs (discharged into the environment) associated to the set of functions required to reproduce the identity of a given socialecological system (Giampietro et al., 2011). The concept of metabolic pattern neatly shows that the nexus between water, energy, and food is determined by forced relations among the structural and functional elements of a complex system. The term "relational analysis" (Rosen, 1958, 1985; Louie, 2009, 2013) indicates the existence of expected patterns of relations over the elements of metabolic networks that are capable of self-reproduction and self-maintenance. It implies a distinction 


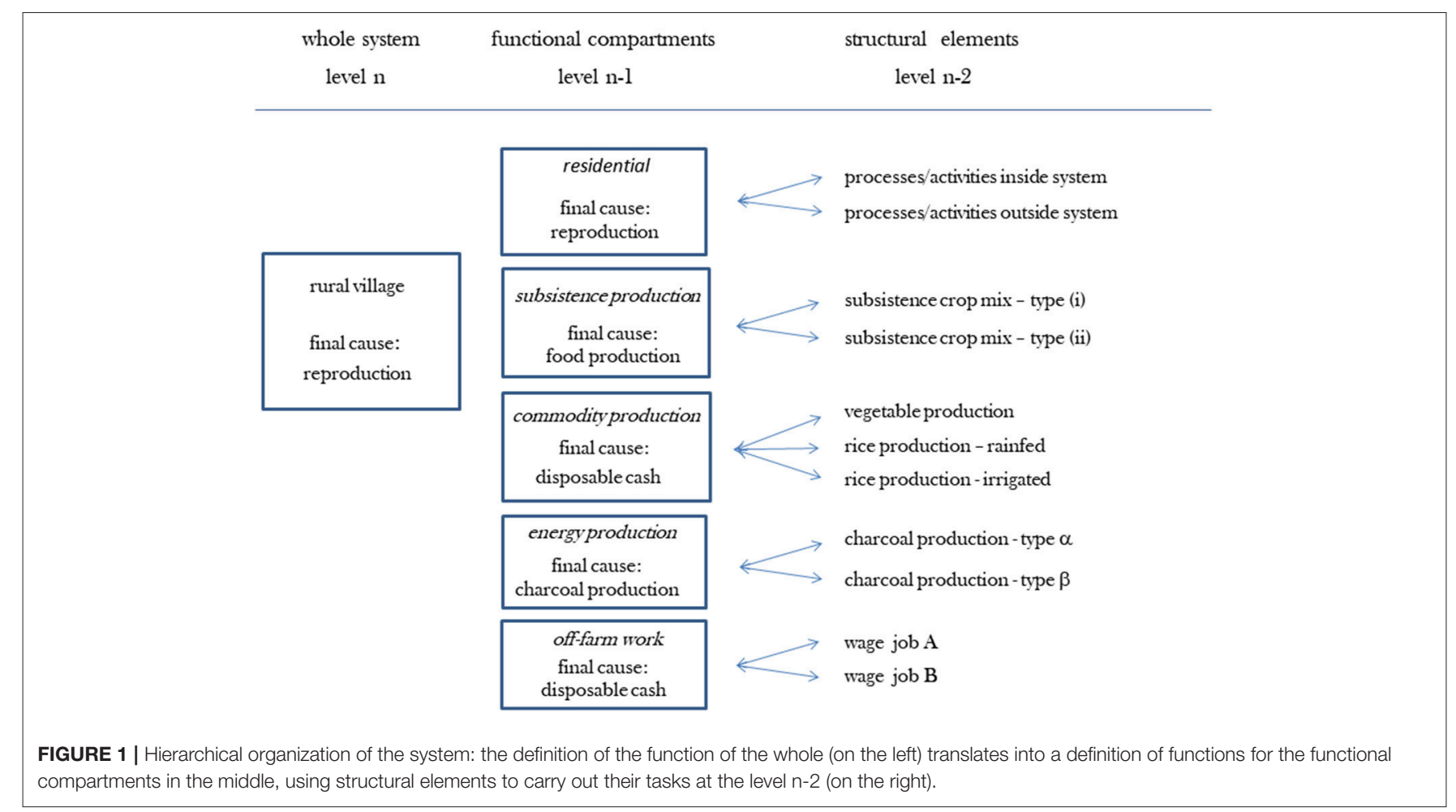

between: (i) inputs and outputs remaining inside the selforganizing system; and (ii) inputs and outputs exchanged with the context. MuSIASEM also borrows from hierarchy theory (Koestler, 1968; Whyte et al., 1969; Allen and Starr, 1982; Salthe, 1985; Ahl and Allen, 1996) in that it explains the complex and impredicative relations among structural and functional elements across different hierarchical levels of organization. In particular, we consider functional elements as the parts of the "black-box" that define the interaction with the embedding context (black-box is level $n$, functional parts are at level $n-1$, the context is level $n+1)$. Each functional compartment is determined by a series of structural elements that are not necessarily homogenous or similar in their biophysical processes (see Figure 1). For example, a functional compartment (vegetable production) may be composed of different combinations of structural elements (processes producing tomatoes, egg-plants, zucchini).

The assignment of structural elements to a given functional element is a semantic decision: the structural elements must share the same final objective (final cause in the jargon of relational analysis) with the functional element to which it is assigned. For example, in Figure 1, vegetable production and rice production belong to the same functional compartment (cash crop production). Different structural elements-that is, processes associated with a defined land-use typology-mapping onto the same final cause will be accounted in the same functional compartment. The structural elements are considered as subparts of the functional components as described in Figure 1 (structural parts are defined at level $n-2$, functional parts at level $n-1$, and the black-box at level $n$ ).
Note that the semantic definition of the relation between structural and functional compartments is subject to a certain level of ambiguity. For example rice production can be mapped onto two different functional compartments, "subsistence production" and "cash crop/commodity production"; charcoal production can be mapped onto "energy production" or "cash crop/commodity production." In the same way, the final causegetting disposable cash-can be obtained in two different ways, relating to two structural elements of different nature: on-farm production requiring land use allocation and off-farm work not requiring land allocation within the system boundaries. All these "bifurcations" can be handled by the accounting framework of MuSIASEM. In fact, MuSIASEM accounting entails a constraint of congruence to avoid double counting (and a messy representation). The sum of the relative sizes of the flows (energy, water, food, and money) and the funds (hours of human activity and hectares of land use) associated with the functional compartments and structural elements (defined at levels $n-1$ and level $n-2$, respectively) must be equal to the total amount of flow and fund elements defined at level n. For example, when the process of charcoal production generates an input (energy flow) consumed by the village, we must include the funds and the flows associated with this production to the final cause of producing energy. On the contrary if the charcoal is sold on the market then the funds and flows associated with this process are included in the functional compartment "getting disposable cash." In fact, when charcoal is produced and sold it does not belong to the energetic metabolism of the village, it becomes just a commodity. In relation to this point, the conditions of congruence-the size of all the flows and funds must remain the same when moving 
across different levels of analysis-guarantee coherence in the analysis.

Thus, an important feature of MuSIASEM is that the simplification of the information space in a given set of categories of accounting-required to generate a quantitative representation-is not semantically closed, as is the case with conventional models. The framework of accounting allows an exploration of the option space generated by the complex set of impredicative relations between structural and functional elements across hierarchical levels and scales: it does not deny the existence of chicken-egg paradoxes or ambiguities in the definition of the parts and sub-parts, rather it handles them. MuSIASEM deals with impredicativity through the use of grammars, that is, a set of expected relations over functional and structural elements that is semantically open. In fact, it may be that changes in external constraints will affect the characteristics of internal processes (top-down causality) or that changes in the internal characteristics of the system will redefine the external constraints (bottom-up causality). In this sense, we prefer the term quantitative storytelling over quantitative analysis to stress that numbers generated in this way only have meaning if properly contextualized in relation to: (i) the special characteristics of the environment; (ii) the special history of the social-ecological system in question; and (iii) the special research question considered.

MuSIASEM can be used in a diagnostic mode, by analyzing the actual metabolic pattern of a system, or in simulation mode, by examining scenarios (e.g., population growth, technical innovation, changing terms of trade).

In conclusion the innovative features of this approach are:

1. It is based on an analysis of relations over patterns (processors are profiles of expected inputs and outputs) and not on relations over numbers (e.g., inputs or output) as is the case in conventional models;

2. It integrates quantitative information referring to different hierarchical scales (describing and combining relevant aspects of the system originating from non-equivalent descriptive domains);

3. It integrates quantitative attributes defined according to different dimensions of analysis (economic, social, technical, ecological) and allows the use of geographic information systems;

4. It handles "impredicativity," that is the ambiguous relation between structural and functional types (chicken-eggs paradox) typically encountered in the analysis of the functioning of complex self-producing systems.

\section{THE IDEA OF PROCESSORS}

An important novel aspect of the approach proposed here compared to earlier work is the use of processors to assign an identity to the metabolic elements of the system. Any metabolic element of a social-ecological system, whether a functional compartment or a structural element, is an open system in itself that expresses an expected pattern of "behavior" in terms of: (i) consumption of inputs; (ii) expression of a useful function coinciding with the supply of useful output(s); and (iii) generation of unwanted by-products. The semantic analog of the "processor" of social-ecological systems is the enzyme for biochemical systems or the production function for economic analysis. The basic idea is that a specific pattern of inputs can be associated to the generation of a specific pattern of outputs. Depending on the scale considered, the expected behavior may be either: (i) reproducing itself (if we are considering the metabolic system as a whole); (ii) expressing a useful function needed to stabilize the larger metabolic system to which the element belongs (if we are considering a functional element); or (iii) transforming a profile of inputs into an expected profile of outputs (if we are considering a structural element making up a functional element). Metabolic elements can be defined as functional elements, when their characteristics are determined by processes taking place on the level above (top-down causality), or structural elements, when their characteristics are determined by processes taking place on the level below (bottom-up causality).

Thus, we describe each metabolic element (either functional or structural) as a processor that establishes a relation between: (i) internal inputs and internal outputs, and (ii) external inputs and external outputs. "Internal" refers to two different typologies of elements that are consumed or produced (flows) and maintained (funds) by the society (societal metabolism). In the jargon of life cycle analysis (LCA), internal elements are described as operating in the "technosphere" and therefore they refer to inputs and outputs determined by processes that are under human control and remaining within the borders of the socio-economic systems. "External" refers to flows that are produced or received by processes outside human control, that is, natural processes and ecosystem services (ecosystem metabolism). In the jargon of LCA these flows are considered as "coming from" or "going to" the biosphere.

As illustrated in Figure 2 a processor is therefore associated with five sets of inputs/outputs:

- $\mathrm{n}_{1}$ : Internal inputs-required flows under human control (e.g., electricity, fuels, blue water, food, monetary flows):

- $\mathrm{n}_{2}$ : Internal inputs-required funds under human control (e.g., hours of human labor, hectares of land use, power capacity):

- $\mathrm{n}_{3}$ : External inputs-required flows extracted from ecosystems (e.g., green water, water extracted from aquifers to generate blue water, ecological services):

- $\mathrm{n}_{4}$ : External outputs-flows that must be discharged into ecosystems (e.g., pollutants, nitrogen from fertilizers, solid waste, GHG emissions):

- $\mathrm{n}_{5}$ : Internal outputs-useful flows or funds generated by metabolic elements and used by other elements in the technosphere (e.g., the useful products of functional and structural elements-supply of charcoal, rice, disposable cash).

The terminology funds and flows refers to the flow-fund model of Georgescu-Roegen in relation to bioeconomic analysis (Mayumi, 2002). A processor (Figure 3), is made of fund elements (inputs of human activity, managed land, power capacity), and this amount of fund elements will remain constant over the time duration of analysis (usually on a year basis). This information 


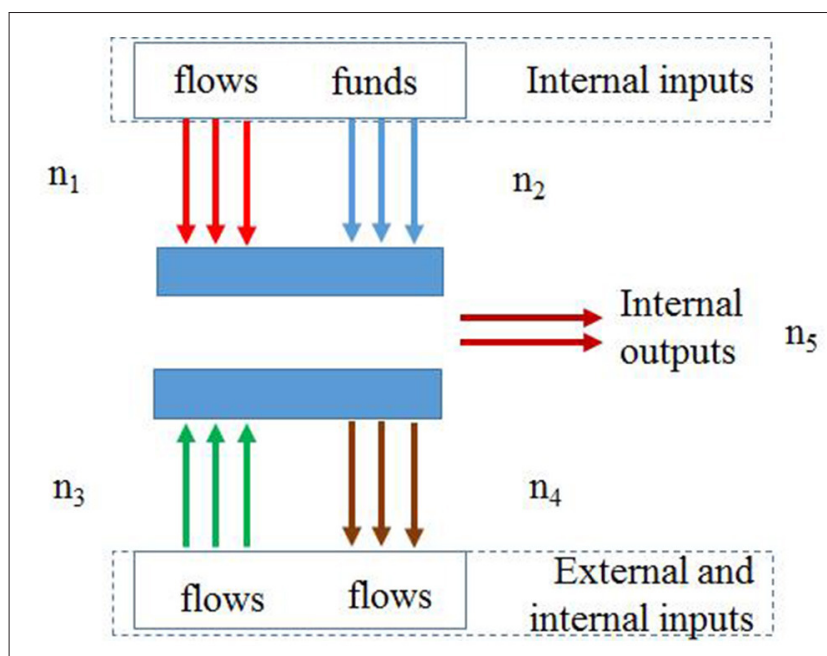

FIGURE 2 | Conceptualization of the expected pattern of inputs and outputs in a processor. Inputs and outputs remaining in the technosphere are internal, those getting from and to the biosphere are external.

can be used to define the size of the processor. The flow elements describe what the processors do: consuming and producing inputs and outputs (energy, food, water, monetary flows). Flows either appear or disappear during the analysis. Therefore, by using the concept of processor we can define: (1) the size of the functional and structural elements looking at quantities of fund elements; and (2) the qualitative characteristics of these elements (benchmark values) looking at the values of flow/fund ratios-e.g., energy per hour of labor, food per hour of labor, etc.

A representation based on processors makes it possible to describe social-ecological systems across different scales. In fact, the characteristics of the different processors of functional elements can be scaled-up to describe the characteristics of the whole village. This translates into defining a higher-level processor by scaling-up the relative quantities of inputs and outputs. The characterization of the given set of relations across scales is illustrated in Figure 4. In order to obtain the scaling, it is essential that the sum of the sizes of funds and flows described in the functional elements is equal to the size of funds and flows (per category) described at the level of the whole. The identification and definition of functional elements requires assigning an identity to the different socio-economic sectors or activities (a definition of why are they needed).

\section{RELATIONAL ANALYSIS OVER FUNCTIONAL ELEMENTS}

In Figure 5 we propose a set of functional elements associated with a charcoal producing village. As discussed earlier (see also Figure 1), functional elements describe the social-ecological system top-down. They explain what the system does in terms of socio-economic activities (what/why): charcoal production (either energy supply or getting disposable cash through commodity production), off-farm work (getting disposable cash through wages), and residential activities (reproducing the fund element "people"). Since this method of representation is semantically open, other functional elements may be added to this set (e.g., cultural, religious activities). What is important is to re-adjust, after the introduction of a new set of functional and structural element, the profile of allocation of funds and flows in order to maintain the congruence of the relative sizes and relative paces and densities across the different representations across levels. As a matter of fact, the "identity" of the social-ecological system in terms of a set of functional elements should be defined on the basis of participatory processes involving the inhabitants of the system.

The definition of the set of functional elements, the definition of their relative sizes, and the definition of the metabolic profile of the various flows (e.g., water, energy, money) in each of the functional elements generate mutual information in the system, also called a "Sudoku effect" in analogy with the Sudoku game (Giampietro and Bukkens, 2015). Sudoku is a popular number puzzle in which one can infer the solution based on a set of congruence constraints and the information already given. Note that the size of the funds and the flows in the processor of the different functional compartments must be compatible with the size and the flows of the set of processors making up the whole (system closure). The quantification of the characteristics of the various processors in relation to the processor of the whole (after considering imports and exports) permits us to study the existence of sets of forced relations ("playing the Sudoku game").

Using the concept of processor, we can define the total size of the funds, in this example: total human activity measured in hours per year $(\mathrm{THA}=$ population $\times 8,760$ ) and total available land within the geographic boundaries (TAL), measured in hectares (see Figure 5). This is the overall size of the village (at level $\mathrm{n}$ ) should be divided among the lower-level functional elements (level $n-1$ ). Both THA and TAL must be distributed over the different functional elements (the categories of human activity and land uses associated with the different processors) in accordance with the socio-economic organization. This entails a competition for the use of these funds across different functional compartments. Therefore, each investment in any one of the functional elements can be considered to have an "opportunity cost" for society (the same amount of funds could be used for a different purpose).

An additional constraint is represented by the qualitative characteristics of the functions expressed by the functional elements. For instance, crop production can only take place on arable land. So additional categories, such as managed land (land uses) and non-managed land, need to be used for organizing the accounting (see Figure 5). This explains why an analysis of functional elements requires also a simultaneous analysis of structural elements carried out to a finer grain (at a smaller scale). The same applies for the fund human activity: Human beings need a given amount of sleep and personal care (nonworking time), heavy work requiring a high level of power can only be carried out by male adults or animal power, etc. It should be noted that by looking at the analysis of functional elements, we can get a diagnostic analysis of the relations between funds and flows inside and across different functional elements. For 


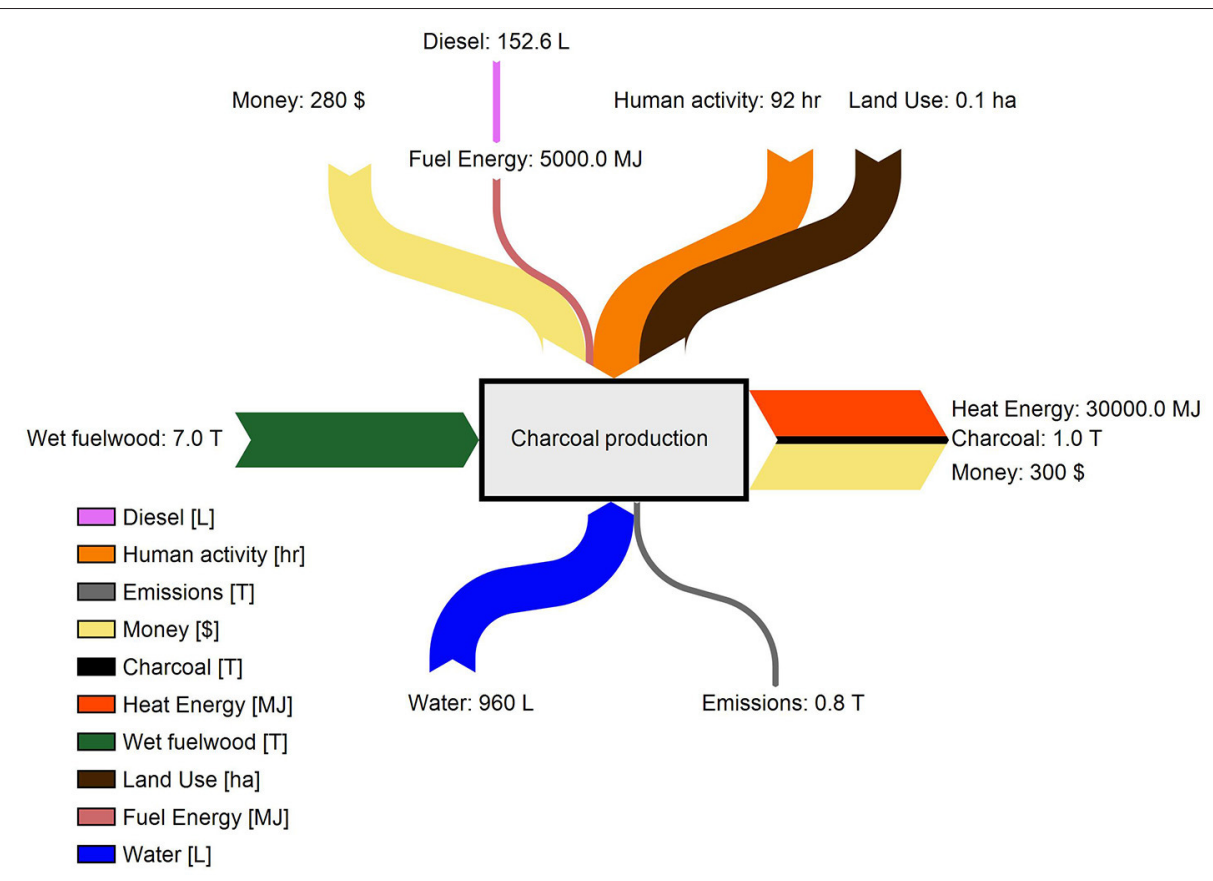

FIGURE 3 | Schematic representation of the charcoal production processor. Data are made up for the purpose of illustration.

Scaling the characteristics of processors of functional elements into the characteristics of a processor describing the whole

Processors functional element

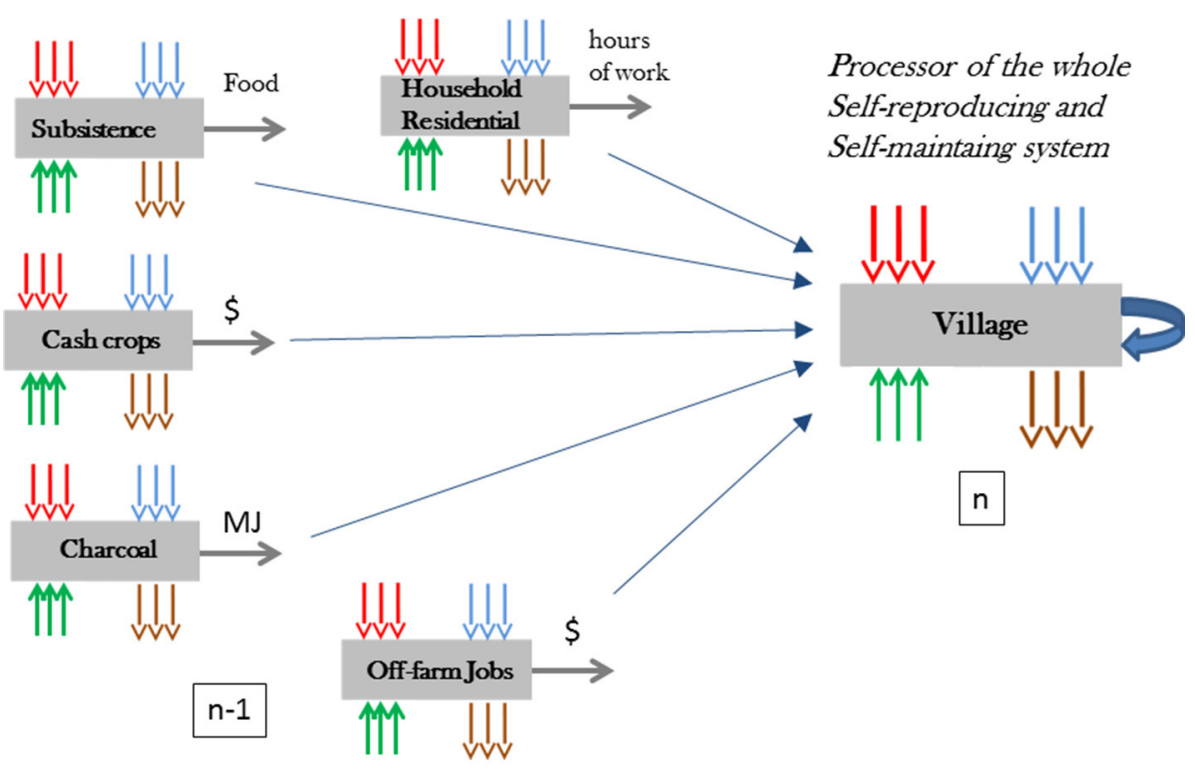

FIGURE 4 | The characteristics of a processor describing the whole society (on the right) are explained using the characteristics of the processors describing functional elements (on the left).

example, one can calculate how much water (flow), managed land (fund), and human labor (fund) is required or how much pollution is generated by a given processor. However, on the basis of a relational analysis of functional elements only, one cannot define the exact location of the associated activities. To have the exact location in space of a specific biophysical process (described 


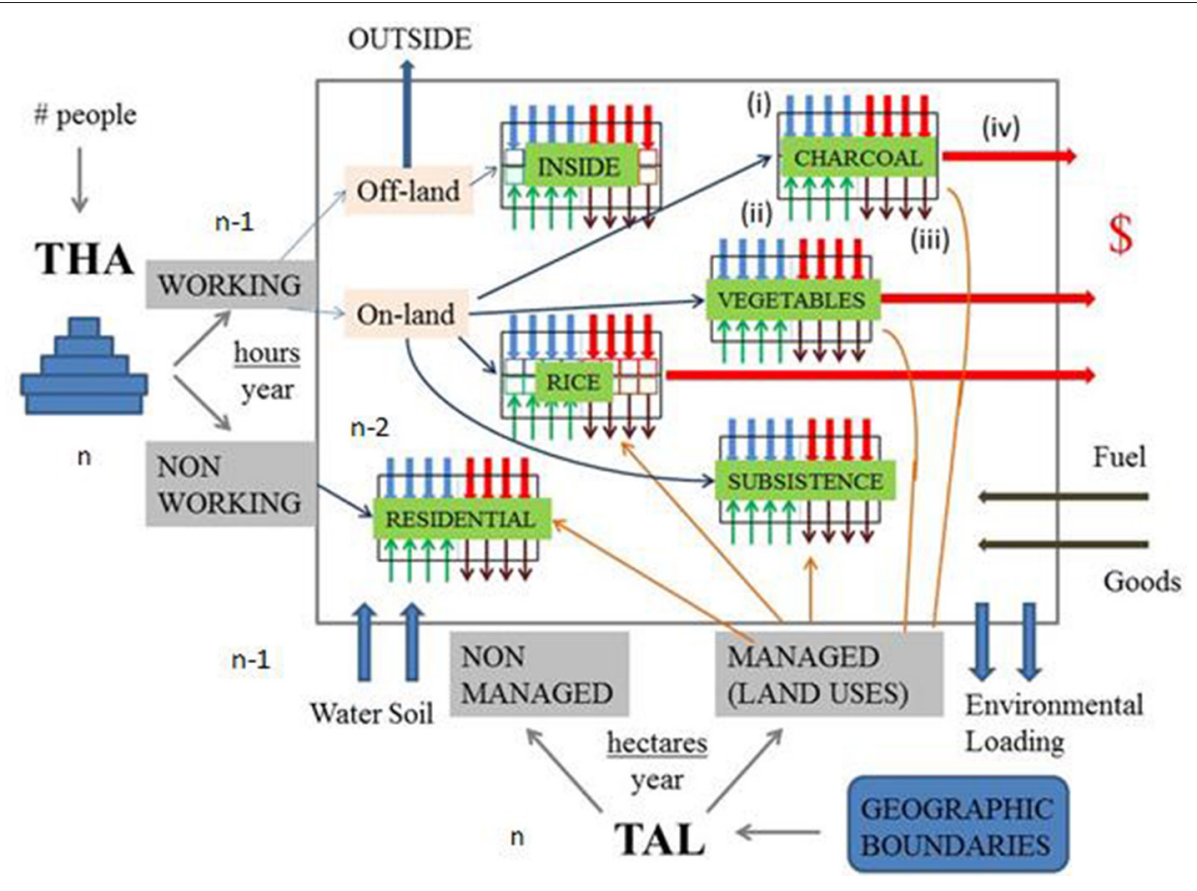

FIGURE 5 | Representation of the functional elements for a charcoal-producing village. Each activity is associated with a processor determining a set of expected relations between inputs, outputs, wastes and emissions. The overall metabolic pattern can be assessed against the constraints provided by the limited availability of human activity (THA) and available land (TAL).

by its specific processor) we should look at the corresponding structural element(s). This can be achieved using a layer in GIS of all the land uses (e.g., typologies of crop production) mapping onto a same functional type (e.g., commodity production). In this way, we can handle a typical predicament of integrated assessment: (i) the accounting of economic flows (internal inputs and outputs coming and going into the techno sphere) can be "translated" into economic variables considering the costs and revenues-prices. But this accounting is not directly associated to specific locations; (ii) the assessment of environmental impacts requires us to locate the exact position of the land use.

In Figure 5 we can also see the inflows and outflows resulting from market transactions. Note that this graph is just a skeleton for the organization of the accounting. The various flows are indicated in semantic terms, but can be quantified adopting different choices of proxy variables. For instance, food may be quantified in terms of $\mathrm{kg}$ of food products (potatoes, beef, papaya, etc.) or kcal of nutrients (proteins, carbohydrates, calories). The same applies to water (blue water and green water) or energy (charcoal, gasoline, or wood). In MuSIASEM, benchmarks, such as charcoal produced per hour of labor, money earned per hectare, food required per person per day, water extraction from the aquifer per day, are used to assess the relative flows. In this way it becomes possible to summarize the balance of the system (whole vs. the sum of all the functional elements-see Figure 4) in relation to the chosen metric for quantifying energy, food, water, human activity, land use, and money flows. This balance has to consider the distinction between flows derived from inside the village and those from outside (imports). This diagnostic analysis is a good starting point to have the big picture of the factors (drivers, states) determining the sustainability on the socio-economic side.

\section{RELATIONAL ANALYSIS OVER STRUCTURAL ELEMENTS}

Structural elements are elements expressing an expected metabolic pattern of inputs and outputs associated with a known process. They have an external referent independent of their function guaranteeing the reliability of the expression of the pattern (e.g., a common blueprint or know-how determining the characteristics of the process). Examples of structural elements are: a hectare of rice cultivated with a given technology, a job providing a known wage, a pattern of behavior of members of a household when out of work. Structural elements are associated with the expression of a specific typology of process and therefore with the expression of an expected profile of inputs and outputs at a given scale. In general the scale of the structural elements is smaller than that of the corresponding functional type.

Indeed, several structural types can feed into one functional type. For instance, as illustrated in Figure 6, all the hectares of crop-land used to cultivate rice with a specific technique (e.g., rain fed) and all the hectares of crop-land used to cultivate rice with another technique (e.g., irrigated) can be aggregated into another category of accounting that is "rice production." In turn, the two structural elements "rice production" and "vegetable production"-referring to actual 


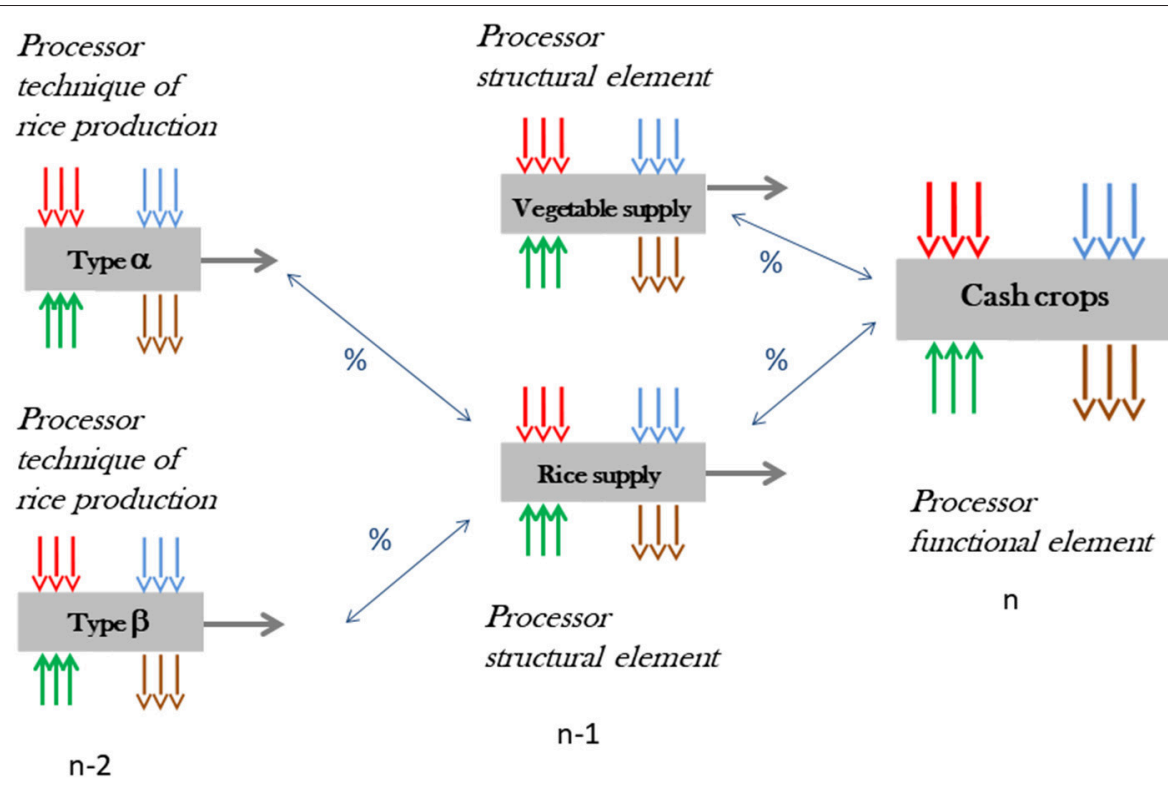

FIGURE 6 | Scaling the representation starting from the characteristics of production techniques (on the left) scaled into the characteristics of structural elements (in the middle) scaled to the characteristics of functional elements (on the right). The scaling can go in the two directions.

processes taking place in specific locations (hectares of land use) with known modalities (yields and labor productivity) can be aggregated into the functional element "cash crop production."

For the operation of scaling down (moving from right to left in Figure 6) it is necessary to obtain information on the characteristics of the structural elements at the local scale. In this way it becomes possible to generate the analysis shown in Figure $\mathbf{6}$ in which different land uses map onto a same category of structural elements. This procedure allows us to study the existence of external constraints-availability and suitability of land, availability of water, effect of pollution, destruction of habitat, etc.

Vice versa, in order to be able to interpret the information given by technical coefficients defined at the local level of land uses - the characteristics of structural elements defined by processors-we have to scale them up to the level of functional elements (moving from left to right in Figure 7. For instance, in this way we can examine how the flows observed at the local level of structural elements "translate" into economic flows associated with imports and exports of inputs and outputs at the level of the whole village. At this point, the importance of handling impredicativity becomes evident. We can use the established set of relations either: (i) to assess the characteristics that would be required by the mix of processors of structural elements (the pattern of production) to achieve the economic performance required by the functional elements, or (ii) to assess what type of economic performance can be achieved by the functional element, given the characteristics and the mix of lower-level structural elements.

The multi-scale analysis permits us to elucidate the nature of costs and benefits at the local scale (e.g., between different technologies to extract water: water pumps powered by wind or diesel), the relevance of these costs in the overall budget of the households at a mesoscale, to finally arrive at how the different performances of households affect the characteristics of the whole village.

In simulation mode, processors can be used to compare the effect of changes in the relative size of structural types that feed into the same functional type. For example, we can compare the profiles of inputs and outputs associated with 1 ton of rice produced by different techniques ( $\alpha$ vs. $\beta$ ) and make projections on how a different mix of the production techniques will affect the land use and overall flows of energy, water, food at the village level. Trade-offs (e.g., 1 ton of rice $\alpha$ requires more energy than rice $\beta$, but less water) can then be evaluated within a larger analysis of the metabolic pattern in relation to the indirect effects that an adjustment in one functional element (rice production) can have on the others in terms of changes in the allocation of land-use, overall production of food for self-consumption or generation of cash income.

An analysis based on structural types and land-use analysis makes biophysical constraints better visible (Serrano-Tovar and Giampietro, 2014). For example, flooded areas are good only for rice production but not for vegetable production. Also, distance to the fields is an important factor in determining labor productivity because commuting diminishes the time available for other activities. Finally an analysis of land use and structural elements allows us to better appreciate how the flows of energy, water, and biomass metabolized by processes under human control affect (in negative ways) the ability of the embedding natural ecosystems to express their metabolic pattern of flows of energy, water, and biomass (Lomas and Giampietro, 2017). 


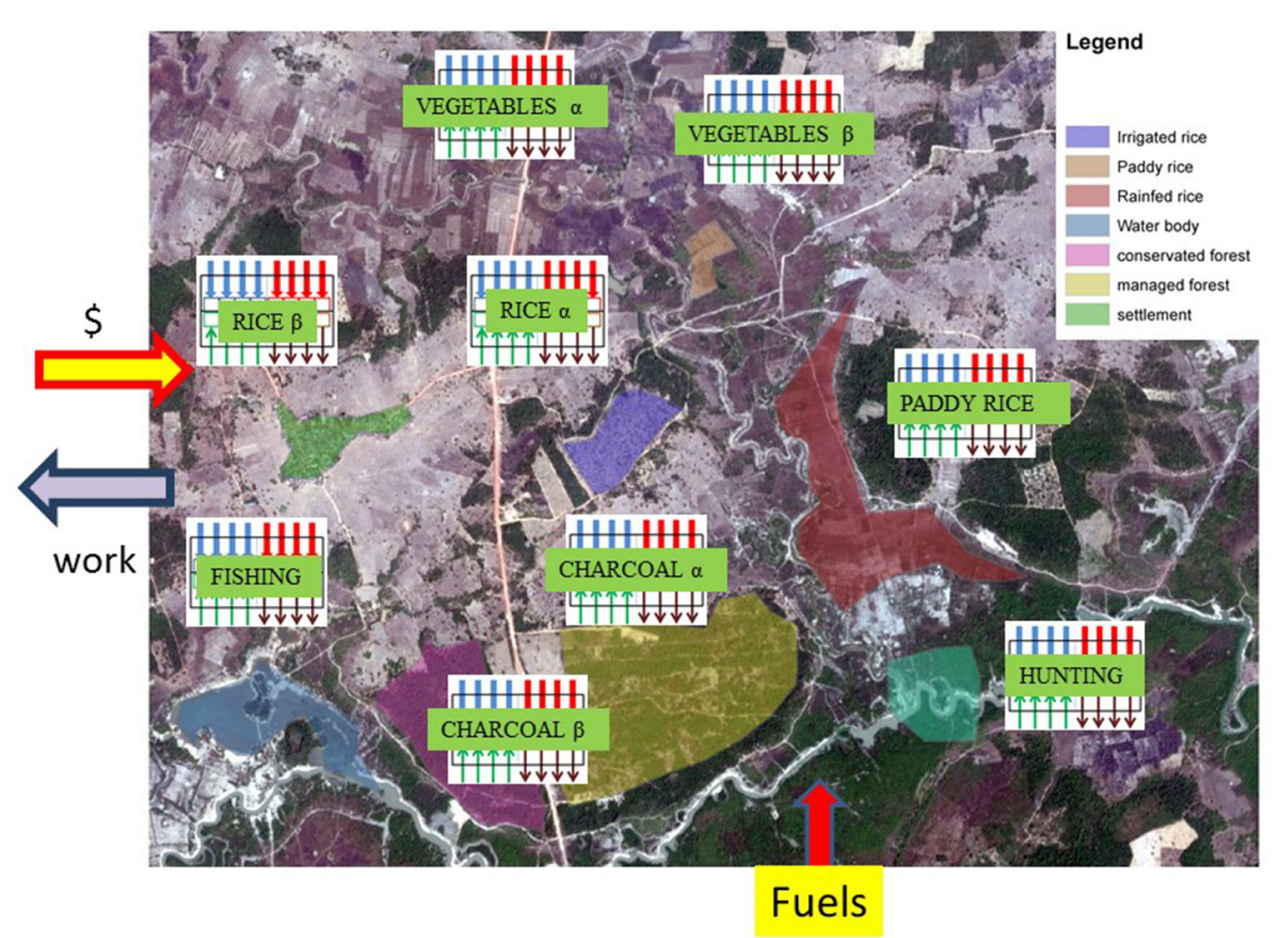

FIGURE 7 | Representation of structural elements (green squares) for a hypothetical charcoal-producing village. For each activity, we show different typologies having different input requirements.

\section{DISCUSSION AND CONCLUSIONS}

In relation to charcoal production in rural villages MuSIASEM can result extremely useful in that it characterizes the functional elements in relation to human time (activity) allocation (the hours of labor/activity required to express the different functions). In many charcoal-producing subsistence villages the opportunity-cost of human time is a key factor determining the observed pattern of activities. Examples are the trade-offs between subsistence vs. cash-crops, and child labor vs. education.

For instance, in the case of the Dong Khuai village in Laos (Yokoyama et al., 2014), an increasing share of the villagers goes working outside the village to bring money inside. The same final cause "getting disposable cash" can be obtained from two different functional elements: producing commodities (that may include charcoal!), something requiring land-uses, or working outside the village, not requiring land uses. Population growth and the movement to a market economy reduce the amount of land available inside the village to collect wood and produce charcoal and increase the opportunity cost of labor. When pressured by these two drivers, villagers tend to invest relatively more human time in earning money through off-farm work and then use the money generated in this way to buy LPG gas. The trade-offs of this substitution can also be assessed by considering the final cause of the functional element "producing energy" and comparing the two structural processes "charcoal production" vs. "generation of income to purchase LPG" that can fulfill the same function. Buying LPG has a much lower opportunity cost of human time than making charcoal, but it increases the dependence on the availability of off-farm jobs and the risk in case of fluctuations in gas prices. These two conditions are beyond the control of the villagers and therefore this trade-off can only be properly assessed at a larger hierarchical level considering a larger scale (the relation between the village and its socio-economic context). The same dilemma is faced in relation to food security. Abandoning self-sufficiency, obtained through the functional compartment "subsistence production," in favor of a fully monetarized economic process-getting cash through wages to buy food-may provide an improvement in living conditions but it may also increase the risks for the villagers.

In this example, we see that the production of charcoal and food can be considered in relation to different perspectives ("food and energy" vs. "disposable cash"). The analysis of the resulting trade-offs depends on the set of relations between the size and the characteristics of the structural and functional elements in the metabolic pattern. How much charcoal and food can be sold, what is the "opportunity cost" of the land, labor and other inputs to be invested in their production, how much land and labor is available. The internal competition for production factors can be related to the problem of children forced to help their parents to collect wood (Yuichiro et al., 2009). When the time of the children is needed to collect wood, we deal with a community constrained by the 
requirement of labor to remain at a low level of education and leisure.

In conclusion, we illustrated that the main logic of the approach consists in establishing a relation among different hierarchical levels and different dimensions of analysis. Characterizing functional elements in relation to the whole system (levels $\mathrm{n}+1, \mathrm{n}, \mathrm{n}-1$ ) the approach bridges the biophysical and economic dimension of sustainability. Characterizing structural elements (levels $\mathrm{n}-2, \mathrm{n}-1, \mathrm{n}$ ) the approach links the technical and ecological dimension of sustainability. The proposed quantitative representation organized over a specified set of functional and structural elements forces the analyst to address the "why, what and how questions": What is produced and consumed? How are goods and services produced and consumed and by whom? Why these goods and services and why these modalities? Why does the society express this specific pattern of functions and not another? A transparent analysis of the what, how and why questions represent an effective application of nexus thinking in the form of quantitative

\section{REFERENCES}

Ahl, V., and Allen, T. F. H. (1996). Hierarchy Theory: A Vision, Vocabulary, and Epistemology. New York, NY: Columbia University Press.

Allen, T. F. H., and Starr, T. B. (1982). Hierarchy Perspectives for Ecological Complexity. Chicago, IL: University of Chicago Press.

Broto, V. C., Allen, A., and Rapoport, E. (2012). Interdisciplinary perspectives on urban metabolism. J. Ind. Ecol. 16, 851-861. doi: 10.1111/j.1530-9290.2012.00556.x

Butz, R. J. (2013). Energy for Sustainable Development Changing land management : a case study of charcoal production among a group of pastoral women in northern Tanzania. Energy Sustain. Dev. 17, 138-145. doi: 10.1016/j.esd.2012.11.001

Chidumayo, E. N., and Gumbo, D. J. (2013). Energy for Sustainable Development The environmental impacts of charcoal production in tropical ecosystems of the world : a synthesis. Energy Sustain. Dev. 17, 86-94. doi: 10.1016/j.esd.2012.07.004

Cottrell, F. (1955). Energy and Society: The Relation between Energy, Social Changes, and Economic Development. New York, NY: McGraw-Hill.

Daniels, P. L. (2002). Approaches for quantifying the metabolism of physical economies: a comparative survey: Part II: review of individual approaches. J. Ind. Ecol. 6, 65-88. doi: 10.1162/108819802320971641

Fischer-Kowalski, M., and Hüttler, W. (1998). Society's metabolism. J. Ind. Ecol. 2, 107-136. doi: 10.1162/jiec.1998.2.4.107

Ghilardi, A., Mwampamba, T., and Dutt, G. (2013). Energy for Sustainable Development What role will charcoal play in the coming decades? Insights from up-to-date fi ndings and reviews. Energy Sustain. Dev. 17, 73-74. doi: $10.1016 /$ j.esd.2013.02.007

Giampietro, M. (2014). "The scientific basis of the narrative of societal and ecosystem metabolism," in Resource Accounting for Sustainability: The Nexus between Energy, Food, Water and Land Use, eds M. Giampietro, R. Aspinall, J. Ramos-Martin, and S. G. F. Bukkens (New York, NY: Routledge), 250.

Giampietro, M., Aspinall, R., Ramos-Martin, J., and Bukkens, S. G. F. (2014). Resource Accounting for Sustainability Assessment: The Nexus between Energy, Food, Water and Land Use. New York, NY: Routledge.

Giampietro, M., and Bukkens, S. G. F. (2015). Analogy between Sudoku and the multi-scale integrated analysis of societal metabolism. Ecol. Inform. 26, 18-28. doi: 10.1016/j.ecoinf.2014.07.007

Giampietro, M., Mayumi, K., and Ramos-Martin, J. (2009). Multiscale integrated analysis of societal and ecosystem metabolism (MUSIASEM): theoretical concepts and basic rationale. Energy 34, 313-322. doi: 10.1016/j.energy.2008.07.020 story-telling and a good starting point to improve research and policy approaches in complex landscapes.

\section{AUTHOR CONTRIBUTIONS}

MG developed the MuSIASEM methodology. RG applied the methodology to charcoal producing systems.

\section{ACKNOWLEDGMENTS}

RG acknowledges the support given by "CONACYT-SENER Sustentabilidad Energética" no. 409781 scholarship. MG acknowledges support by the European Union's Horizon 2020 research and innovation programme under grant agreement no. 689669 (MAGIC). We are indebted to Sandra G. F. Bukkens for her useful comments and suggestions and for editing the manuscript. This work reflects the authors' view only; the funding agencies are not responsible for any use that may be made of the information it contains.

Giampietro, M., Mayumi, K., and Sorman, A. H. (2011). The Metabolic Pattern of Societies: Where Economists Fall Short. New York, NY: Routledge.

Koestler, A. (1968). The Ghost in the Machine. New York, NY: Macmillan.

Lomas, P. L., and Giampietro, M. (2017). Environmental accounting for ecosystem conservation: linking societal and ecosystem metabolisms. Ecol. Modell. 346, 10-19. doi: 10.1016/j.ecolmodel.2016.12.009

Lotka, A. J. (1922). Contribution to the energetics of evolution. Proc. Natl. Acad. Sci. U.S.A. 8, 147-151. doi: 10.1073/pnas.8.6.147

Lotka, A. J. (1956). Elements of Mathematical Biology. New York, NY: Dover Publications Inc.

Louie, A. (2009). More Than Life Itself: A Synthetic Continuation in Relational Biology (Categories) Vol. 1. Berlin: Walter de Gruyter.

Louie, A. H. (2013). The Reflection of Life. New York, NY: Springer.

Madrid-López, C., and Giampietro, M. (2015). The water metabolism of socioecological systems: reflections and a conceptual framework. J. Ind. Ecol. 19, 853-865. doi: 10.1111/jiec. 12340

Martinez-Alier, J. (1987). Ecological Economics: Energy, Environment and Society. Oxford: Basil Blackwell.

Mayumi, K. (2002). The Origins of Ecological Economics: The Bioeconomics of Nicholas Georgescu-Roegen. New York, NY: Routledge.

Mwampamba, T. H., Ghilardi, A., Sander, K., and Chaix, K. J. (2013). Dispelling common misconceptions to improve attitudes and policy outlook on charcoal in developing countries. Energy Sustain. Dev. 17, 75-85. doi: 10.1016/j.esd.2013.01.001

Ostwald, W. (1907). The modern theory of energetics. Monist 17, 481-515. doi: 10.5840/monist190717424

Ostwald, W. (1911). Efficiency. Independent 71, 867-871.

Rosen, R. (1958). A relational theory of biological systems. Bull. Math. Biophys. 20, 245-260. doi: 10.1007/BF02478302

Rosen, R. (1985). "Organisms as causal systems which are not mechanisms: an essay into the nature of complexity," in Theoretical Biology and Complexity, eds I. W. Richardson, A. H. Y. Louie, and R. Rosen (Orlando, FL: Academic Press), 165-203. doi: 10.1016/B978-0-12-597280-2.50008-8

Salthe, S. N. (1985). Evolving Hierarchical Systems: Their Structure and Representation. New York, NY: Columbia University Press.

Serrano-Tovar, T., and Giampietro, M. (2014). Multi-scale integrated analysis of rural Laos: studying metabolic patterns of land uses across different levels and scales. Land Use Policy 36, 155-170. doi: 10.1016/j.landusepol.2013.08.003

Soddy, F. (1926). Virtual Wealth and Debt: The Solution of the Economic Paradox. London: George Allen \& Unwin.

Swyngedouw, E. (2006). Circulations and metabolisms: (Hybrid) Natures and (Cyborg) cities. Sci. Cult. 15, 105-121. doi: 10.1080/09505430600707970 
White, L. A. (1943). Energy and the evolution of culture. Am. Anthropol. 45, 335-356. doi: 10.1525/aa.1943.45.3.02a00010

Whyte, L. L., Wilson, A. G., and Wilson, D. (1969). Hierarchical Structures. New York, NY: Elsevier Science.

Wolman, A. (1965). The metabolism of cities. Sci. Am. 213, 178-190. doi: 10.1038/scientificamerican0965-178

Yokoyama, S., Okamoto, K., Takenaka, C., and Hirota, I. (2014). Integrated Studies of Social and Natural Environmental Transition in Laos. Tokyo: Springer.

Yuichiro, N., Okamoto, K., and Boulidam, S. (2009). Time-geographic analysis on natural resource use in a village of the vientiane plain. Southeast Asian Stud. 47, 426-450. doi: 10.11518/hgeog.2008.0.509.0

Zipf, G. K. (1941). National Unity and Disunity. Bloomington, IN: The Principia Press, inc.

Zulu, L. C. (2010). The forbidden fuel: charcoal, urban woodfuel demand and supply dynamics, community forest management and woodfuel policy in Malawi. Energy Policy 38, 3717-3730. doi: 10.1016/j.enpol.2010. 02.050

Zulu, L. C., and Richardson, R. B. (2013). Energy for sustainable development charcoal, livelihoods, and poverty reduction : evidence from sub-Saharan Africa. Energy Sustain. Dev. 17, 127-137. doi: 10.1016/j.esd.2012.07.007

Conflict of Interest Statement: The authors declare that the research was conducted in the absence of any commercial or financial relationships that could be construed as a potential conflict of interest.

Copyright $\odot 2017$ González-López and Giampietro. This is an open-access article distributed under the terms of the Creative Commons Attribution License (CC BY). The use, distribution or reproduction in other forums is permitted, provided the original author(s) or licensor are credited and that the original publication in this journal is cited, in accordance with accepted academic practice. No use, distribution or reproduction is permitted which does not comply with these terms. 